\title{
Preventive Effects of Ananas comosus Juice on Obesity Risk Factors in Female Wistar Rats
}

\author{
Judith F. Ahounou Aïkpe1,2*, André Hamadou1,3, Lamou Bonoy33, Analbert T. Kotinan³, \\ Joachim D. Gbenou'2, Pierre H. Dansou' ${ }^{1}$
}

\author{
${ }^{1}$ Research Unit in Exercise Physiology (URPEF), University of Abomey Calavi, Porto-Novo, Bénin \\ ${ }^{2}$ Laboratory of Pharmacognosy and Essential Oils (LAPHE), University of Abomey Calavi, \\ Cotonou, Benin \\ ${ }^{3}$ Laboratory of Biology Physical Activity, National Institute of Youth and Sports (NIYS), Yaoundé, Cameroon \\ Email: `judifam@yahoo.fr
}

How to cite this paper: Ahounou Aikpe, J.F., Hamadou, A., Bonoy, L., Kotinan, A.T., Gbenou, J.D. and Dansou, P.H. (2020) Preventive Effects of Ananas comosus Juice on Obesity Risk Factors in Female Wistar Rats. Open Journal of Applied Sciences, 10, 534542 .

https://doi.org/10.4236/ojapps.2020.108037

Received: July 14, 2020

Accepted: August 18, 2020

Published: August 21, 2020

Copyright (c) 2020 by author(s) and Scientific Research Publishing Inc. This work is licensed under the Creative Commons Attribution International License (CC BY 4.0).

http://creativecommons.org/licenses/by/4.0/

\begin{abstract}
The present study aim was to assess the preventive effects of Ananas comosus juice consumption on the risk factors of obesity in female Wistar rats. 108 rats were tested for 90 days. After randomization, they were shared out into six groups including four experimental groups (GTc, GPlp, GEns and GBrS) and two control groups $\left(\mathrm{G}_{\mathrm{CT}}^{+}\right.$and $\mathrm{G}_{\mathrm{CT}}^{-}$). The control group consumed 1.20 $\mathrm{ml}$ of distilled water, the experimental rats received in oral, $1.20 \mathrm{ml}$ of drinks made from the different parts of Ananas comosus fruit. The measurements of morphometric and biochemical parameters were carried out on Day 0 (D0), Day 30 (D30), Day 60 (D60) and Day 90 (D90). The analysis showed that compared to the positive control rats, the consumption of the various drinks slowed down significantly $(\mathrm{P}<0.001)$; the evolution of the morphometric and biochemical parameters likely to induce obesity in experimental rats which have an increase in a protective factor (HDL; $\mathrm{P}<0.001)$. These results indicate that consumption of different parts of Ananas comosus's juices had preventive effects on risk factors related to obesity. Moreover, the fruit juice treatment has been found to be more effective.
\end{abstract}

\section{Keywords}

Obesity, Ananas comosus, Morphometric, Biochemical Parameters

\section{Introduction}

Public health problems in underdeveloped countries, once dominated by infectious and parasitic pathologies, are increasingly contrasted by a galloping evolu- 
tion of nontransmissible pathologies [1] (WHO, 2003). Among these metabolic diseases, obesity appears as a pandemic of the century because it is developing at high speed [1]. considering its worldwide expansion and its consequences on physical, psychological and social well-being, obesity has aroused significant interest within the scientific community [2]. Several strategies are implemented for its management. The aim of obesity treatment is to ensure sufficient weight loss, to maintain the results obtained and to treat complications by means, among other drugs, psychotherapy or surgery [3]. For this, the current WHO recommendations for the treatment of obesity aim to reduce weight by around 5 to $10 \%$. Studies show that a $5 \%$ decrease in weight considerably reduces the risk of developing chronic diseases and improves general physical condition [4]. Regular physical and sporting activities of moderate intensity and/or consumption of foods rich in fiber and unsaturated fats improve the lipid and morphometric profile [5] [6] [7].

Furthermore, regular consumption of the juices from different parts of Ananas comosus and its association with physical activity such as swimming can reduce weight, abdominal circumference and fat mass while improving biochemical parameters in obese rats [8]. If these curative treatments combining physical activity with Ananas comosus juice have already shown satisfactory results at the end of the experiment, their effects during the obesity induction process still seem to be poorly understood. Therefore, it would be interesting to study the preventive effects of Ananas comosus consumption on morphometric and biochemical parameters related to obesity. The objective of this study is to assess the preventive effects of consumption of juices made from different parts of the pineapple on the risk factors for obesity in rats. Specifically, it is a matter of to determine the type of pineapple juice that best delays the onset of obesity. This work is motivated to popularize the consumption of endogenous products that can intervene in the prevention of metabolic disorders such as obesity.

\section{Materials and Methods}

\subsection{Plant Material}

It consists of the fruits of Ananas comosus and synthesized bromelain. Ananas comosus fruits, of Cayenne smooth variety, harvested in Mbamkomo (Mfoundi Department, Center Region of Cameroun) were used to make raw juices. The plant is identified with the national herbarium of Yaoundé where each specimen is kept under sample $n^{\circ} 18648 / \mathrm{SRF} / \mathrm{CAM}$.

The synthesized bromelain is supplied in capsules by "SMART City". Each vegetable capsule contains $500 \mathrm{mg}$ of bromelain with $1000 \mathrm{GDU}$ of digestive activity.

\subsection{Animal Material}

The animals material is composed of young female Wistar rats used (Rattus norvegicus). for the experiment are female albino rats of the wistar strain (Rattus norvegicus). They are 90 days old with an average weight $121.45 \pm 8.65 \mathrm{~g}$ at the 
start of the experiment. They were acclimated to the conditions of the Pharmacology and Biochemistry Laboratory of the Faculty of Medicine and Biomedical Sciences of the University of Yaoundé I. These animals were reared at $25^{\circ} \mathrm{C}$ $30^{\circ} \mathrm{C}$ temperature, $70 \%$ to $80 \%$ for relative humidity and $12 \mathrm{~h} / 12 \mathrm{~h}$ for light/dark duration. Their have food and water ad libitum.

\subsection{Rat Nutrition}

During the first phase of breeding which lasted 03 months, the rats received a normal diet for their maintenance and their growth. After this phase, they were subjected to a high-calorie and hyperlipidic diet aimed at inducing obesity. However, the experimental group simultaneous received hyperlipid food and preventive treatment based on juices made from different parts of Ananas comosus. This second phase also lasted 03 months. The formulation of the rat diet is based on the recommendations of the [9] American Institute of Nutrition (1997), with some modifications according to a local adaptation made by the National Veterinary Laboratory (LAVANET).

\section{Distribution of rats (Table 1)}

The animals were accommodated in 06 metabolic cages at the dimension by $29.5 \mathrm{~cm} \times 40 \mathrm{~cm}$ in base and $17 \mathrm{~cm}$ in height.

\section{Preparation of reference solution}

The reference solution is prepared with a capsule of synthesized bromelain dosed at $500 \mathrm{mg}$ which is diluted in $500 \mathrm{ml}$ of distilled water.

\subsection{Experimental Protocol}

Three types of juice are prepared according to the different parts of the Ananas comosus: the central stem (Tc), the pulp (Plp) and the whole consisting of the central stem and the pulp (Ens). Thus, after sorting, washing and peeling, the fruits or the different isolated parts (central stem or pulp) are crushed and filtered in a centrifuge, then bottled and stored in the refrigerator at a temperature of $4^{\circ} \mathrm{C}$.

The reference group received $10 \mathrm{mg} / \mathrm{kg}$ of bromelain [10], knowing that $100 \mathrm{~g}$ of fresh Ananas comosus contains $100 \mathrm{mg}$ of bromelain.

Table 1. Organization of rats in experimental group and control group.

\begin{tabular}{cc}
\hline Groups & Number of rats \\
\hline Negative control Group $\left(\mathrm{G}_{\mathrm{CT}}^{-}\right)$ & 18 rats \\
Positive control Group $\left(\mathrm{G}_{\mathrm{CT}}^{+}\right)$ & 18 rats \\
Juice Group of Central stem of Ananas $c .\left(\mathrm{G}_{\mathrm{Tc}}\right)$ & 18 rats \\
Juice Group of Pulp of Ananas $c .\left(\mathrm{G}_{\mathrm{plp}}\right)$ & 18 rats \\
Juice Group of Central stem and pulp of Ananas $c .\left(\mathrm{G}_{\mathrm{Ens}}\right)$ & 18 rats \\
Juice Group jus of synthesized bromelain $\left(\mathrm{G}_{\mathrm{Brs}}\right)$ & 18 rats \\
Total & 108 rats \\
\hline
\end{tabular}


The animals consumed $1.20 \mathrm{ml}$ of pineapple juice. Bromelain is concentrated in the central stem compared to the pulp.

The experimental rats consumed a daily amount of $1.20 \mathrm{ml}$ by gavage according to their batch in the morning between 7 hours and 9 hours for 90 days. The control rats received $1.20 \mathrm{ml}$ of distilled water during the same period and at the same times (Figure 1).

$\underline{\text { D0 }}$

- Measure: Body Mass (BM), Circumference abdomen (Ca), Fatty Mass (FM) -Blood Sample

-Oral admnistration

- food and water ad libitum

Dav 1 to Dav 28

Oral admnistration

- food and water ad libitum

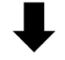

Dav 29

Oral admnistration

- food and water ad libitum

- On an empty stomach $12 \mathrm{~h}$

Day 30

- Measure: Body Mass (BM), Circumference abdomen (Ca), Fatty Mass (FM)

-Blood Sample

-Oral admnistration

- food and water ad libitum

Dav 31 à Day 58

Oral admnistration ;

- food and water ad libitum

\section{Day 59}

Oral admnistration

- food and water ad libitum

- On an empty stomach $12 \mathrm{~h}$

Day 60

- Measure: Body Mass (BM), Circumference abdomen (Ca), Fatty Mass (FM)

-Blood Sample

-Oral admnistration

- food and water ad libitum

Day 61 to Day 88

- Oral admnistration

- food and water ad libitum

Day 89

- Oral admnistration

- food and water ad libitum

- On an empty stomach $12 \mathrm{~h}$

Day 90

Measure: Body Mass (BM), Circumference abdomen (Ca), Fatty Mass (FM)

-Blood Sample

-Oral admnistration

- food and water ad libitum

Figure 1. Measurement of study parameters. 


\subsection{Statistical Analysis}

The results are expressed as Mean values \pm Standard Error of Mean (SEM). The data collected were organized using MS Excel 2010 software which made it possible to observe the central trends and dispersion characteristics such as the mean and the standard deviation, as well as the evolution curves of the parameters and finally, create diagrams illustrating the digital summaries of the information sought. The software $\mathrm{R}$ version 3.2.3 was used to carry out the statistical tests, in particular the Wilcoxon test which was used to compare the mean values of the parameters obtained at the beginning and at the end of the experience.

Furthermore, the comparison of effects between the treatments required the implementation of an analysis of variance (ANOVA) with the treatment as a fixed factor. A filing between the treatments was obtained using the StudentNewman-Keuls test. The difference between two means is significant if $\mathrm{P}<0.05$ $\left({ }^{*}\right)$, very significant if $\mathrm{P}<0.01\left({ }^{* *}\right)$ and highly significant if $\mathrm{P}<0.001\left(^{(* *)}\right.$.

\section{Results}

At the start of this study, the rats had an average weight of $121.45 \pm 8.65 \mathrm{~g}$, abdominal circumference of $12.33 \pm 0.67 \mathrm{~cm}$ and a fat mass of $1.15 \pm 0.017 \mathrm{~g}$.

\subsection{Effects of Ananas comosus Juice on Morphometric Parameters}

The mean values of the body mass, abdominal circumference and fatty mass of the rats submited to a high-calorie diet and various treatments show several modifications. Treatments with Ananas comosus juice or bromelain had effects on rats parameters. After 90 days of experimentation, except for the abdominal circumference which had a significant increase $(\mathrm{p}<0.05 ; 8.10 \%)$ the rats which consumed the juice had, the body mass, body fat and abdominal circumference increased very significantly $(\mathrm{p}<0.01)$ in all groups. The large increasing variations are pronounced in the groups of positive control rats. These average values are illustrated in Figures 2(a)-(c).

\subsection{Comparison of Final Values of Morphometric Parameters of Rats}

The final mean values of the morphometric parameters of rats are represented in Figures 3(a)-(c). The body mass, abdominal circumference, and fatty mass of animals experienced have less evolution $(\mathrm{p}<0.001)$ compared to the positive control rats. Otherwise, the lowest mean values were observed in the group of rats which consumed the juice of the whole fruit.

The average values of biochemical parameters of rats subjected to a hyperlipidic diet and Ananas comosus juice or synthesized bromelain show various variations after 90 days of preventive treatment. The total cholesterol increased significantly $(\mathrm{P}<0.01 ; 13 \%)$ in the group of rats having juice of the pulp. Any variation in LDL-cholesterol was significant in all the experimental groups. The triglycerides have increased $(\mathrm{P}<0.05 ; 68.00 \%)$ in the group of rats treated with 


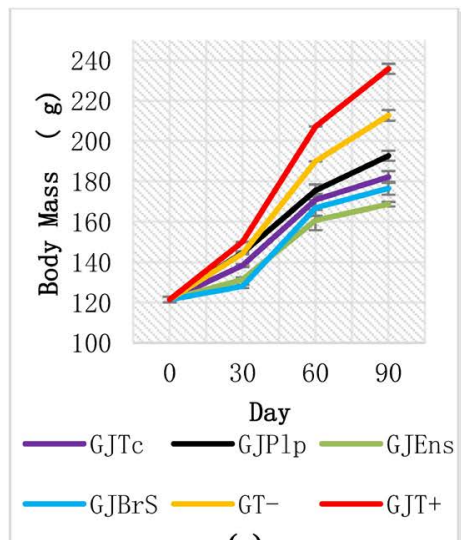

(a)
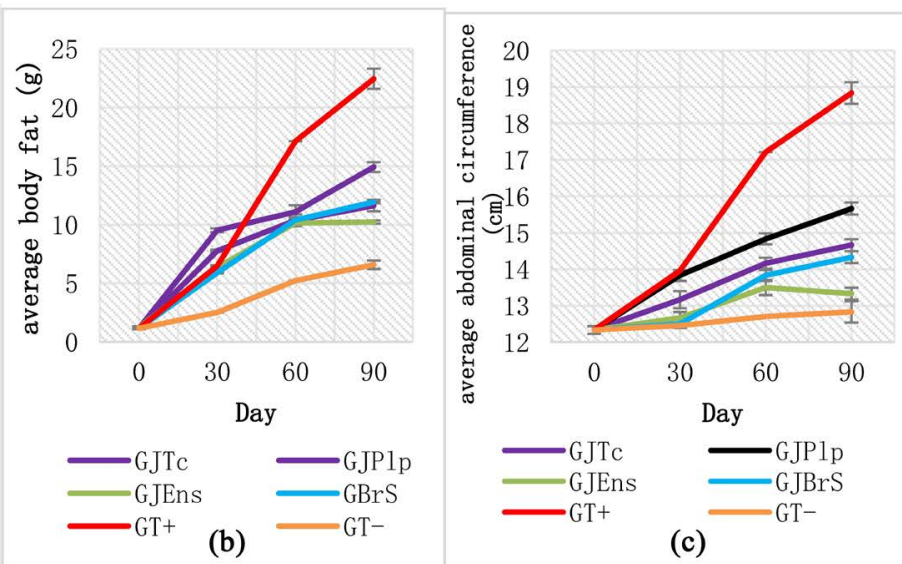

(c)

GTC: Ananas comosus central stem juice group; GPlp: Ananas comosus pulp juice group; GEns: Group of central stem juice and Ananas comosus pulp; GBrS: Synthetic bromelain juice group; GT+: positive control group; GT-: negative control group.

Figure 2. Evolution of rat morphometric parameters during treatment. (a) Body Mass; (b) Fatty Mass; (c) Circumference abdomen.

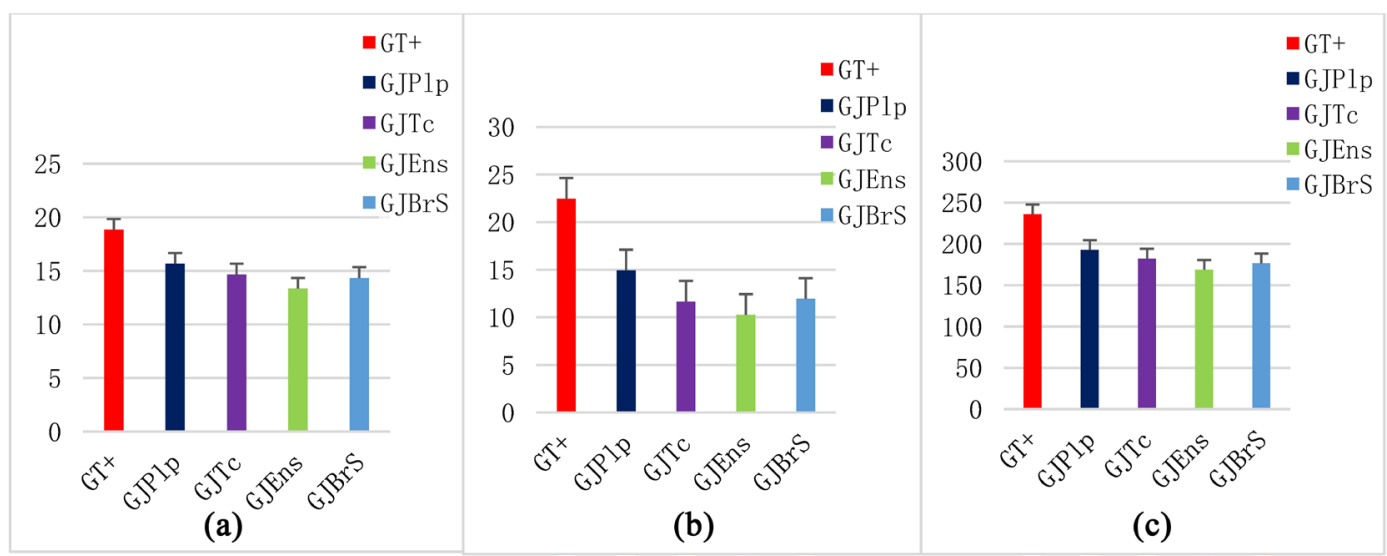

$\mathrm{GT}+=$ positive control group, GJPlp = group of rats treated with Ananas comosus pulp juice, GJTc = group of rats treated with central stem juice, GJEns = roup of rats treated with the juice of the central stem + Ananas comosus pulp; $\mathrm{GBrS}=$ group of rats treated with synthetic bromelain. $\Delta$ : variation With a significant if $\mathrm{p}<0.05\left(^{*}\right)$; very significant if $\mathrm{p}$ $<0.01\left(^{* *}\right)$; highly significant if $\mathrm{p}<0.001\left(^{* * *}\right)$.

Figure 3. Final mean values of morphometric parameters. (a) Body Mass; (b) Fatty Mass; (c) Circumference abdomen.

pulp juice. The glycemia decreased by $13 \%$ in rats having consumed the juice of the whole "central stem + pulp" and $12 \%$ in the rats of the central stem group. These values are illustrated in Figures 4(a)-(e).

\section{Discussion}

The comparison of morphometric and biochemical parameters values during the experience allowed to observe significant modifications $(P<0.01)$. These variations compared to the values of negative control rats (normo-weighted rats) showed no significant difference. The consumption of the juices did not have any harmful effects on the growth of the experimental rats. The comparative analysis of the final values of the morphometric parameters, between the experimental rats 

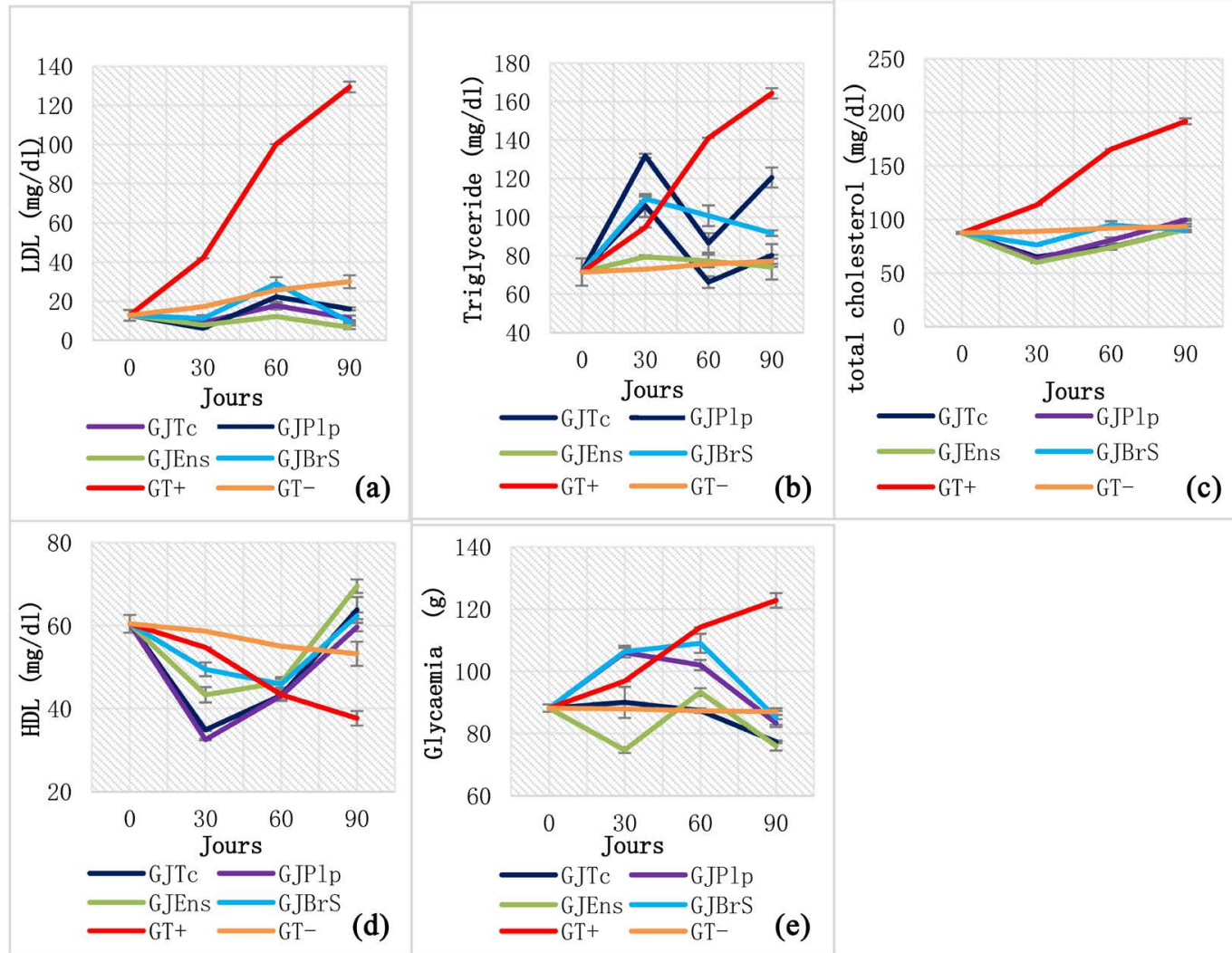

GJT: Ananas comosus central stem juice group; $\mathrm{GJ}_{\mathrm{Plp}}$ : Ananas comosus pulp juice group; $\mathrm{GJ}_{\mathrm{Ens}}$ : Group central stem juice and Ananas comosus pulp $\mathrm{G}_{\mathrm{Br}}$ : Group bromelain juice synthesized $\mathrm{G}_{\mathrm{T}+}$ : positive control group; $\mathrm{G}_{\mathrm{T} .:}$ negative control group.

Figure 4. Biochemical parameters. (a) LDL-cholesterol; (b) Triglycerides; (c) Total cholesterol; (d) HDLcholesterol; (e) Glycaemia.

and the positive control rats revealed a significant difference $(\mathrm{P}<0.001)$. Moreover, it should be noted that these variables experienced the smallest changes in the group of rats which consumed the juice of the whole $\mathrm{p}$ Ananas comosus fruit. These variations in the mean values of the morphometric parameters between the experimental rats and the positive control rats on the one hand and between the different groups of rats subjected on the other hand, that the consumption of Ananas comosus juice are due to the richness of the fruit in dietary fiber, bromelain and trace elements.

These modifications, which are more pronounced in the group of rats that consumed the juice of the whole Ananas comosus fruit, could be explained by an uneven distribution of bromelain in the Ananas comosus fruit. The bromelain is more concentrated in the central stem compared to the pulp [11]. This justifies its dose-dependent effects on the study parameters. Our results are in line with those of the authors [8] [9] [10] who showed the beneficial effects of the consumption of pineapple juice on the morphometric and anthropometric parameters.

The comparison of the final values of biochemical parameters within the groups during the experience made it possible to note various modifications. With regard to the final values of the experimental rats and those of the negative 
control rats, no significant difference $(\mathrm{P}>0.05)$ was observed. This could be explained by the fact that the preventive treatment did not have harmful effects on the growth of rats during obesity induction. With regard to the comparative reading of the final values of the biochemical parameters (total cholesterol, HDL-cholesterol, LDL-cholesterol, triglycerides and glycemia) between the positive control rats and the experimental rats, a significant difference $(\mathrm{P}<0.001)$ was revealed. The normalized evolution of biochemical parameters $(\mathrm{P}<0.001)$ during the experience would be due to the consumption of raw Ananas comosus juice. Which is in perfect agreement with literature. Indeed, several studies have demonstrated the influence of bromelain and dietary fiber on the levels of atherogenic blood lipids in animals and humans [6] [8] [12] as well as on blood sug$\operatorname{ar}[12][13]$.

\section{Conclusion}

After 90 days of experimentation, the various preventive treatments based on Ananas comosus juice have influenced the evolution of risk factors related to obesity. The different treatments reduced the morphometric and biochemical parameters of the experimental rats. Moreover, the best modifications are observed in the group having consumed the juice of the whole "central stem with pulp". Thus, Ananas comosus juice made from the whole fruit "central stem with pulp" have the most positive effects on the risk factors linked to obesity in female albino wistar.

\section{Conflicts of Interest}

The authors declare no conflicts of interest regarding the publication of this paper.

\section{References}

[1] OMS (2003) Organisation Mondiale de la Santé, Rapport Obésité: Prévention et prise en charge de l'épidémie mondiale, Genève. http://whqlibdoc.who.int/trs/WHO TRS 894 fre.pdf

[2] Molarius, A., Seidell, J.C. and Sans, S. (2000) Educational Level, Relative Body Weight, and Changes in Their Association over 10 Years: An International Perspective from the WHO MONICA Project. American Journal of Public Health, 90, 1260 1268. https://doi.org/10.2105/AJPH.90.8.1260

[3] World Health Organization (1998) Obesity, Preventing and Managing the Global Epidemic. Report of a WHO Consultation on Obesity, World Health Organization, Geneva, $276 \mathrm{p}$.

[4] Bertrais, S., Beyeme-Ondoua, J.P., Czernichow, S., Galan, P., Hercberg, S. and Oppert, J.M. (2005) Sedentarity Behaviors, Physical Activity and Metabolic Syndrome in Middle-Aged French Subjects. Obesity Research, 13, 936-944. https://doi.org/10.1038/oby.2005.108

[5] Hamadou, A., Mbouh, S., Ahounou Aïkpe, J.F., Gbenou, J.D. and Dansou, P.H. (2018) Effets d'un programme d'exercices physiques sur les paramètres anthropométriques, hémodynamiques et physiques des femmes en surcharge pondérale au 
Cameroun. Cahiers du CBRST: Médecine et Santé Publique, 57-75.

[6] Chobotova, K., Vernallis, A.B. and Majid, F.A.A. (2010) Bromelain's Activity and Potential as an Anti-Cancer Agent: Current Evidence and Perspectives. Cancer Letters, 290, 148-156. https://doi.org/10.1016/j.canlet.2009.08.001

[7] Ley, C.M., Tsiami, A., Ni, Q. and Robinson, N. (2011) A Review of the Use of Bromelain in Cardiovascular Diseases. Zhong Xi Yi Jie He Xue Bao, 9, 702-710. https://doi.org/10.3736/jcim20110702

[8] Hamadou, A., Ahounou, J.F., Agbodjogbe, K.W.D., Mibo'o, P., Guessogo, W.R., Gbenou, J., Ngogang, J. and Dansou, H.P. (2017) Effets de la consommation des jus de "Ananas comosus» sur les paramètres morphométriques et le taux des lipides sanguins athérogènes chez les obèses. J. Rech. Sci. Univ. Lomé(Togo), 19, 165-176.

[9] Sripanidkulchai, B., Wongpanich, V., Laupattarakasem, P., Suwansaksri, J. and Jirakulsomchok, D. (2001) Diuretic Effects of Selected Thai Indigenous Medicinal Plants in Rats. Journal of Ethnopharmacology, 75, 185-190. https://doi.org/10.1016/S0378-8741(01)00173-8

[10] Hamadou, A., Ahounou Aïkpe, J., Ebal Menye, E., Ndjaga, D., Gbenou, J., Ngogang, J. and Dansou, P. (2016) Effets cumulés de la consommation des jus d'ananas et de la nage sur les paramètres morphométriques et lipidiques chez les rats obèses. Cahiers du CBRST, 56-79.

[11] Maurer, H.R. (2001) Bromelain: Biochemistry, Pharmacology and Medical Use. Cellular and Molecular Life Sciences, 58, 1234-1245. https://doi.org/10.1007/PL00000936

[12] Kelley, D.E. and Goodpaster, B.H. (2001) Effects of Exercise on Glucose Homeostasis in Type 2 Diabetes Mellitus. Medicine and Science in Sports and Exercise, 33S, 495-501. https://doi.org/10.1097/00005768-200106001-00020

[13] Boule, N.G., Haddad, E., Kenny, G.P., Wells, G.A. and Sigal, R.J. (2001) Effect of Exercise on Glycemic Control and Body Mass in Type 2 Diabetes Melitus. A Meta-Analysis of Controlled Clinical Trials. JAMA, 286, 1218-1227. https://doi.org/10.1001/jama.286.10.1218 